\title{
Phosphogypsum purification for plaster production: A process optimization using full factorial design
}

\author{
Raida Moalla ${ }^{1}$, Manel Gargouri ${ }^{2}$, Foued Khmiri ${ }^{3}$, Lotfi Kamoun ${ }^{3}$, Moncef Zairi ${ }^{{ }^{\dagger}}$ \\ ${ }^{1}$ Laboratory 3E, Sfax National School of Engineers, PB 1173, 3038, University of Sfax, Tunisia \\ ${ }^{2}$ National Agency for Promotion of Scientific Research, 1002 Lafayette, Tunisia \\ ${ }^{3}$ Tunisian Chemical Group Research Directorate, DRU Sfax -3000 Sfax, Tunisia
}

\begin{abstract}
The phosphogypsum (PG) is a byproduct of the phosphate fertilizers manufacture. The world production estimated to 200 million tons per year induces environmental threats and storage problems, which requires strict policies to limit pollution and encourage its valorization. This paper presents a purification process of the crude PG including treatment with a diluted sulfuric acid, floatation, filtration and washing. The purified PG is used to produce plaster. The process optimization was conducted using a full factorial design. The significant factors considered in the experimental study are temperature $\left(X_{1}\right)$, volume of sulfuric acid solution $\left(X_{2}\right)$ and PG quantity $\left(X_{3}\right)$. The main effects and interaction effects of these factors on the responses of the $\% \mathrm{P}_{2} \mathrm{O}_{5}, \% \mathrm{~F}$, Total Organic Carbon (TOC) $\left(\mathrm{mg}^{-\mathrm{kg}^{-1}}\right.$ ) and pH were analyzed. The optimum conditions for $\mathrm{X}_{1}, \mathrm{X}_{2}$ and $\mathrm{X}_{3}$ were found to be $60^{\circ} \mathrm{C}, 3 \mathrm{~L}$ and $1 \mathrm{~kg}$, respectively and the optimized $\mathrm{pH}$ values was found to be 6.2 . Under these conditions, $60 \%$ of $\mathrm{P}_{2} \mathrm{O}_{5}, 95 \%$ of Fluorine and $98 \%$ of TOC were removed from PG. The predicted values were found approximately the same as the experimental ones. The plaster produced with purified PG was found to have similar properties to that produced from natural gypsum.
\end{abstract}

Keywords: Factorial design, Impurities, Optimization, Phosphogypsum, Purification

\section{Introduction}

The phosphogypsum (PG) is a solid byproduct generated by the manufacture of phosphate fertilizers during the production of phosphoric acid [1]. The PG is composed of hydrated calcium sulfate mixed with some impurities such as $\mathrm{P}_{2} \mathrm{O}_{5}$, fluorine, organic matter, heavy metals and radioactive elements [2, 3]. For each ton of produced phosphoric acid, five tons of PG is generated [4]. The worldwide production of PG quantities is between 100 and 280 million tons per year [5, 6], which induces environmental threats and available storage areas problems [7]. Generally, the PG is dumped in the vicinity of the production plants in large stockpiles causing atmospheric pollution and contamination of groundwater, superficial water and soils [8-11]. Therefore, a strict policy is deemed to be an essential measure to limit pollution and encourage the valorization of PG [12]. Actually, the worldwide reuse of PG is only $15 \%$ of the total PG produced [13], in some applications as plaster manufacturing, cement production [14-18], roadway construction [19], agriculture [20], solid brick and raw building block [21, 22].

The PG purification techniques can be divided into three different types: physical, thermal and chemical. The physical treatments were based on the particle size separation while the thermal one consisted of heating the PG at different temperatures [14]. The PG chemical treatment includes mixing with aqueous ammonium hydroxide solution and aqueous citric acid solution [23]. Also, the PG treatment with a mixture of sulfuric acid and silica or hot aqueous ammonium sulphate permitted to get rid of the impurities [14].

Although such treatments produce a good purified PG quality, which can substitute the natural gypsum, but the treatment of PG using sulfuric acid solutions remain preferred in the industry due to its availability in the phosphoric acid plants [24].

Several researchers noted the effectiveness of the PG treatment using sulfuric acid. Jarosinski et al. [25] adapted a method of leaching PG with dilute sulfuric acid solution to recover rare earth elements, followed by production of anhydrite from the purified PG by recrystallisation in concentrated sulfuric acid solution. The results have shown that the undesirable impurities

Received May 4, 2017 Accepted July 18, 2017

${ }^{\dagger}$ Corresponding author

Email: moncef.zairi@enis.rnu.tn

Tel: +216-74-274-088 Fax: +216-74-275-595 
were considerably reduced and the obtained anhydrite can be used for plaster production. Van Der Merwe and Strydom [26] and Lokshin et al. [27, 28] have described a method to purify PG by a dilute sulfuric acid treatment or by a combined thermal and sulfuric acid treatment. A significant amount of impurities was successfully removed by these treatments and the treated PG can substitute natural gypsum in Portland cement. Aliedel et al [29] used a full factorial methodology (considering four factors) to optimize PG purification process using sulfuric and nitric acid solutions.

Hammas-Nasri et al [24] performed a purification process for concentrating rare earth elements from Tunisian PG on a double leaching of $\mathrm{PG}$ with diluted sulfuric acid at $60^{\circ} \mathrm{C}$.

According to the most researches, temperature, sulfuric acid concentration, solid /liquid ratio and stirring time were the most frequently operating parameters affecting the PG purification process [25-26, 29-30].

In most studies, these factors are analyzed independently which may lead to an under estimate of their combined effect. Hence, to overcome this problem, a methodology based on the study of the main effects and the interactions between operating variables using the full factorial design methodology is considered [31].

In the current study, a purification process of PG was developed. The latter is composed of four steps, namely mixture of PG with dilute sulfuric acid solution, floatation, filtration and washing. The three most important experimental factors in different ranges affecting the purification process of PG are temperature, the volume of aqueous sulfuric acid solution and the quantity of PG. In order to adjust the purification process, a full factorial design (FFD) methodology was applied to test the significance of factors and their relative interaction [32, 33]. Regression models were also applied in order to best represent factors interactions through their best fit to the experimental data [34]. Recently, several researchers have used regression models in several fields, such as forecasting the inflow of a dam reservoir by using Auto Regressive Moving Average (ARMA) and Auto Regressive Integrated Moving Average (ARIMA) models and comparing them with the static and dynamic artificial neural networks [35]. Regression models are also used to assess radiation -based models versus the FAO Penman- Monteith (FPM) model to determine the best model under different climatic conditions [36] and to study the effect of the length of recorded data to achieve reliable accuracy for monthly rainfall estimations [37]. Moreover, regression models were applied to irrigation management under different scenarios [38], to estimate the area equipped for irrigation under different scenarios [39] and to estimate the potential evapotranspiration $\left(\mathrm{ET}_{0}\right)$ in Arid, Semiarid, Mediterranean and very humid climates considering climate change and magnitudes of extreme events [40].

A regression model is presented for the response variable: \% $\mathrm{P}_{2} \mathrm{O}_{5}, \%$ F, Total Organic Carbon (TOC) (mg. $\mathrm{kg}^{-1}$ ) and $\mathrm{pH}$ as a function of temperature, volume of aqueous sulfuric acid solution and the quantity of PG. A statistical approach based on response surface methodology (RSM) was used to optimize operating conditions in the process of purification.

The ranges of operating factors were chosen by considering literature data on the PG purification using sulfuric acid solution.
According to the most reported studies, the optimum concentration of sulfuric acid solution is $5 \%[25,26]$. The contact time and agitation speed were chosen of $30 \mathrm{~min}$ and $150 \mathrm{rpm}$, respectively based on the previous study [26, 29, 30].

A temperature of $30^{\circ} \mathrm{C}$ which is the most usually used was chosen as the minimum level in our study whiles the highest one was selected as $60^{\circ} \mathrm{C}$ [24-27]. The solid /liquid ratio has been studied in the range of $1: 1$ to $1: 4[25,26,30]$. The maximum volume of sulfuric solution in the present case was set to $3 \mathrm{~L}$ while the minimum one is $1 \mathrm{~L}$. The range of PG quantity, chosen based on previous studies, is 1 to $2 \mathrm{~kg}[28,30]$.

However, none of the previous reports investigated the combined effect of temperature, volume of aqueous sulfuric acid solution and the quantity of PG on the PG purification process nor evaluated the decrease of the impurities that could be obtained under optimal process conditions. The novelty of this investigation was to use a full factorial design of the experimental program in order to study the effects of the process variables at different levels as well as their interactions. Moreover, the RSM was applied in this study to define optimal condition for the PG purification process with the aim of practical application of the process and not only the technical feasibility. The purified PG obtained under optimal conditions was characterized by chemical analysis, $\mathrm{pH}$ and radioactivity measurements. The purified PG was calcined to produce plaster. The physical properties of the final product were also discussed.

\section{Materials and Methods}

The PG samples used in this study were obtained from the PG stockpile at Sfax city, Tunisia. The average chemical composition of the PG samples is given in Table 1. The PG is mostly (about $94.8 \%)$ made up of calcium sulfate dihydrate $\left(\mathrm{CaSO}_{4} .2 \mathrm{H}_{2} \mathrm{O}\right)$ or gypsum. The remaining components, expected $\mathrm{SiO}_{2}(3.76 \%)$, are present at low percentages $\left(\mathrm{P}_{2} \mathrm{O}_{5}(1.54 \%), \mathrm{F}(1.3 \%)\right.$, TOC $(0.7 \%)$ and $\left.\mathrm{Na}_{2} \mathrm{O}+\mathrm{K}_{2} \mathrm{O}(0.3 \%)\right)$. It should be noted that the $\mathrm{pH}$ of PG samples is around 3.9, indicating the high acidity of the PG.

Table 1. Major Element Contents of the PG Samples

\begin{tabular}{cc}
\hline Constituent & Weight (\%) \\
$\mathrm{CaO}$ & 30.7 \\
$\mathrm{SO}_{4}$ & 52.7 \\
$\mathrm{P}_{2} \mathrm{O}_{5}$ & 1.54 \\
$\mathrm{SiO}_{2}$ & 3.76 \\
$\mathrm{~F}$ & 1.3 \\
$\mathrm{Fe}_{2} \mathrm{O}_{3}$ & 0.03 \\
$\mathrm{Al}_{2} \mathrm{O}_{3}$ & 0.09 \\
$\mathrm{MgO}$ & 0.01 \\
$\mathrm{Na}_{2} \mathrm{O}$ & 0.29 \\
$\mathrm{~K}_{2} \mathrm{O}$ & 0.01 \\
$\mathrm{TOC}$ & 0.7 \\
Fire loss (\%) & 20.09 \\
\hline
\end{tabular}




\subsection{Purification of Phosphogypsum}

The purification experiments were conducted in a stirred tank reactor of $10 \mathrm{~L}$ volume, which was immersed in a thermostatic bath to keep the temperature constant throughout the reaction. The reactor was loaded with a quantity of PG and a volume of aqueous sulfuric acid solution $\left(5 \% \mathrm{H}_{2} \mathrm{SO}_{4}\right)$. The experiments were carried out for solution temperatures of $30^{\circ} \mathrm{C}$ and $60^{\circ} \mathrm{C}$. The stirring was set at $150 \mathrm{rpm}$ for $30 \mathrm{~min}$. The solution was floated for 30 to $45 \mathrm{~min}$ using a floatation cell. The foam of floatation is formed of humic substances already present in the PG. Then, the pulp was filtered through a funnel, washed with water (1.5 $\mathrm{L}$ per $1 \mathrm{~kg}$ of $\mathrm{PG}$ ) and dried $24 \mathrm{~h}$ at $65^{\circ} \mathrm{C}$ (Fig. 1).



Fig. 1. Flow diagram for phosphogypsum purification process.

\subsection{Radioactivity Measurements}

Activity concentrations of ${ }^{226} \mathrm{Ra},{ }^{228} \mathrm{Ac},{ }^{232} \mathrm{Th},{ }^{40} \mathrm{~K}$ and ${ }^{212} \mathrm{~Pb}$ were measured in samples of PG using a typical non-destructive nuclear technique at the INSTN laboratory of the National Institute of Nuclear Science and Technology, Tunisia. This analysis was performed using $\mathrm{\gamma}$ - ray spectrometer equipped with a high pure germanium detector coaxial p-type HPGe with $80 \%$ relative efficiency. Samples were packed in $100 \mathrm{~cm}^{3}$ cans and sealed for about one month to ensure equilibrium between ${ }^{226} \mathrm{Ra}$ and its daughter products, before being taken for gamma-ray spectrometric analysis. The ${ }^{226} \mathrm{Ra}$ activities were determined by taking the mean activity of three separate photo peaks of its daughter nuclides: ${ }^{214} \mathrm{~Pb}$ at 295 and $352 \mathrm{keV}$, and ${ }^{214} \mathrm{Bi}$ at $609 \mathrm{keV}$.

The ${ }^{232} \mathrm{Th}$ content was determined by measuring the intensities of the 911 and $968 \mathrm{keV}$ gamma-ray peaks from ${ }^{228} \mathrm{Ac}$. The potassium content was determined from the $1,460 \mathrm{keV}$ gamma-ray peak of ${ }^{40} \mathrm{~K}$. The concentration of ${ }^{212} \mathrm{~Pb}$ was determined from the 239 $\mathrm{keV}$ gamma-ray peak.

\subsection{Full Factorial Design}

The three factors investigated in this study were temperature (factor $\mathrm{X}_{1}$ ); volume of aqueous sulfuric acid solution (factor $\mathrm{X}_{2}$ ), and PG quantity (factor $\mathrm{X}_{3}$ ). The influence of these factors variations on the responses of the $\% \mathrm{P}_{2} \mathrm{O}_{5}\left(\mathrm{Y}_{1}\right)$, \% F(Y $\left.\mathrm{Y}_{2}\right)$, TOC $\left(\mathrm{mg} \cdot \mathrm{kg}^{-1}\right)$ $\left(\mathrm{Y}_{3}\right)$ and $\mathrm{pH}\left(\mathrm{Y}_{4}\right)$ was evaluated using a $2^{3}$ FFD. A total of 8 experimental runs were performed. The range limits for each factor
Table 2. Factors and Levels Used in the Factorial Design

\begin{tabular}{cccc}
\hline Factor & $\mathbf{X}_{\mathbf{1}}\left({ }^{\circ} \mathbf{C}\right)$ & $\mathbf{X}_{\mathbf{2}}(\mathbf{L})$ & $\mathbf{X}_{\mathbf{3}}(\mathbf{k g})$ \\
\hline Low Limit $(-1)$ & 30 & 1 & 1 \\
High Limit $(+1)$ & 60 & 3 & 2 \\
\hline
\end{tabular}

Table 3. Design Matrix and the Results of the 23 Full Factorial Design

\begin{tabular}{cccccccc}
\hline Experiment & $\mathbf{X}_{\mathbf{1}}$ & $\mathbf{X}_{\mathbf{2}}$ & $\mathbf{X}_{\mathbf{3}}$ & $\begin{array}{c}\mathbf{Y}_{\mathbf{1}} \\
\mathbf{( \% )}\end{array}$ & $\begin{array}{c}\mathbf{Y}_{2} \\
\mathbf{( \% )}\end{array}$ & $\begin{array}{c}\mathbf{Y}_{3} \\
\left(\mathbf{m g . k g}^{-1}\right)\end{array}$ & $\mathbf{Y}_{\mathbf{4}}$ \\
\hline 1 & -1 & -1 & -1 & 0.86 & 0.82 & 1,167 & 5.43 \\
2 & +1 & -1 & -1 & 0.79 & 0.56 & 439 & 5.32 \\
3 & -1 & +1 & -1 & 0.65 & 0.18 & 496 & 6.11 \\
4 & +1 & +1 & -1 & 0.65 & 0.12 & 205 & 6.16 \\
5 & -1 & -1 & +1 & 0.67 & 1.01 & 1,321 & 4.94 \\
6 & +1 & -1 & +1 & 0.77 & 1.02 & 1,520 & 4.92 \\
7 & -1 & +1 & +1 & 0.55 & 0.21 & 145 & 5.75 \\
8 & +1 & +1 & +1 & 0.64 & 0.10 & 87 & 6.18 \\
\hline
\end{tabular}

were assigned the values of $(-1)$ and $(+1)$, respectively (Table 2). The $\mathrm{X}_{1}$ factor varied between 30 and $60^{\circ} \mathrm{C}$, the $\mathrm{X}_{2}$ between 1 and $3 \mathrm{~L}$ and $\mathrm{X}_{3}$ between 1 and $2 \mathrm{~kg}$ [41].

The responses of the experimental design were investigated using Statgraphics Centurion XVI software [42]. The analysis was performed through the plotting of Pareto charts and response surface and the analysis of the variance. The design matrix, presented in Table 3, shows 8 experiments issued from combinations of $\mathrm{Xi}$ factors variations and their corresponding responses Yi.

The regression equation based on the first-order model with three operating variables and their interaction terms are given by the following expression:

$$
\begin{aligned}
Y_{i}= & b_{0}+b_{1} X_{1 i}+b_{2} X_{2 i}+b X_{3 i}+b_{12}\left(X_{1 i} X_{2 i}\right)+ \\
& b_{13}\left(X_{1 i} X_{3 i}\right)+b_{23}\left(X_{2 i} X_{3 i}\right)
\end{aligned}
$$

Where $Y_{i}$ is the response $\left(Y_{1}, Y_{2}, Y_{3}\right.$ and $\left.Y_{4}\right), b_{0}$ the constant; $b_{i}$ the linear coefficient; $b_{i j}$ the interaction coefficients and $X_{i}$ is the dimensionless variables $\left(\mathrm{X}_{1}\right.$ for temperature, $\mathrm{X}_{2}$ for the volume of solution and $\mathrm{X}_{3}$ for $\mathrm{PG}$ quantity) [43, 44].

\section{Results and Discussion}

The aim of the FFD was to find the significant factors on the process and the optimum set of their values to fix the process results on the preferred conditions. The design of the FFD for three control factors using the Statgraphics Centurion XVI software is presented in Table 3 for the 8 experiments responses of the process $\% \mathrm{P}_{2} \mathrm{O}_{5}, \% \mathrm{~F}$, TOC $\left(\mathrm{mg}_{\mathrm{kg}}{ }^{-1}\right)$ and $\mathrm{pH}$.

\subsection{Model Fitting and Statistical Analysis}

The purification experiments were conducted in a random order to determine the effect of the factors on four characteristic responses: \% $\mathrm{P}_{2} \mathrm{O}_{5}, \% \mathrm{~F}$, TOC (mg.kg-1) and $\mathrm{pH}$. The Analysis of the Variance (ANOVA) was performed to determine the statistical 

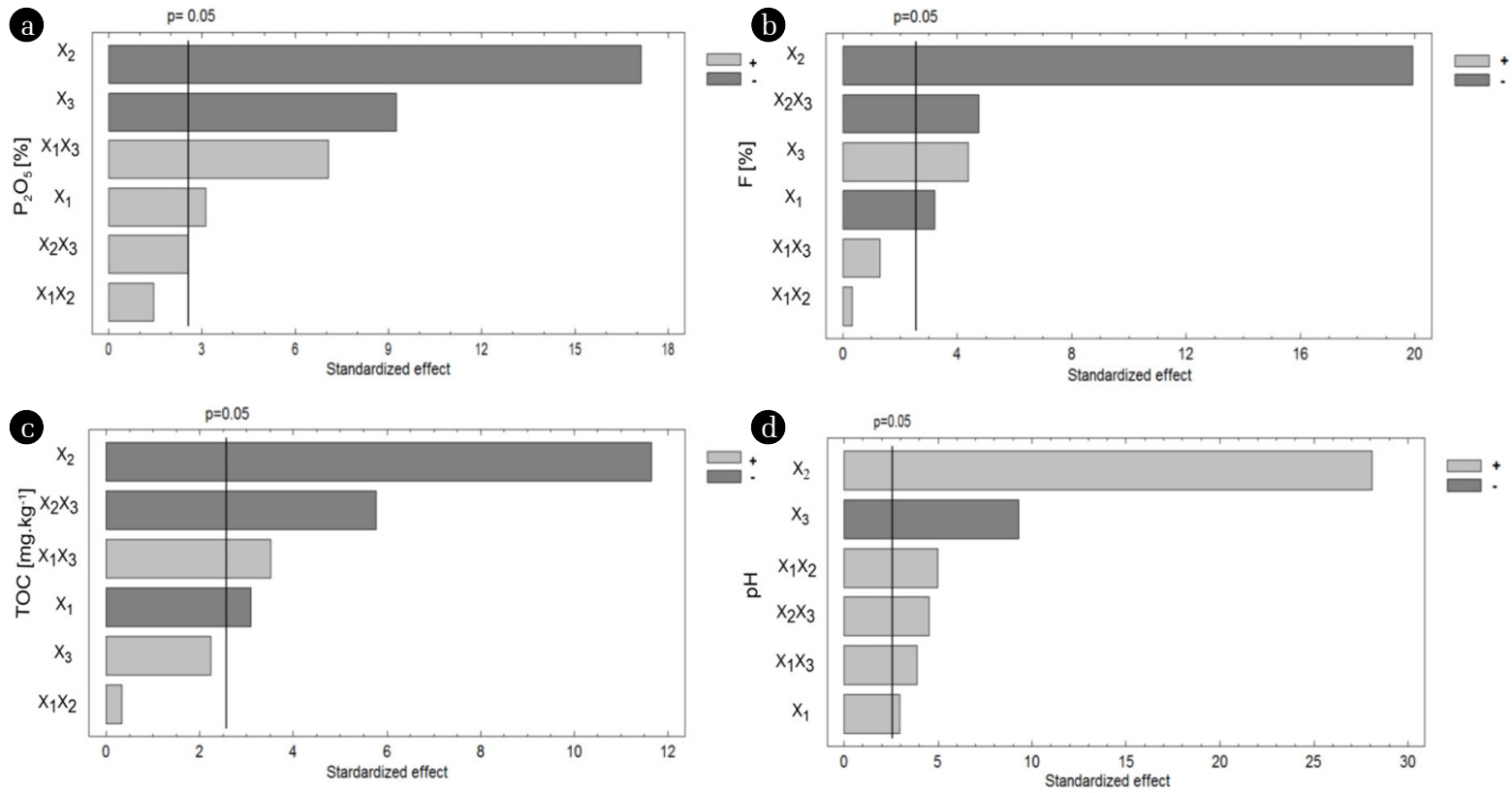

Fig. 2. Pareto chart of standardized effects for responses: (a) $\% \mathrm{P}_{2} \mathrm{O}_{5}$, (b) $\% \mathrm{~F}$, (c) TOC (mg.kg $\mathrm{Tg}^{-1}$ ) and (d) pH. The black color corresponds to negative influence and the grey one to positive influence on the design factors.

Table 4. Statistical Analysis of the Results of the Factorial Experimentation

\begin{tabular}{|c|c|c|c|c|c|c|}
\hline Response & Factor & Regression coefficient & Sum of squares & Standardb error & F-value & $p$-value \\
\hline \multirow[t]{7}{*}{$\mathrm{Y}_{1}$} & Constant & 1.31944 & & & & \\
\hline & $\mathrm{X}_{1}$ & -0.0062037 & 0.00173611 & 0.0133333 & 9.77 & 0.0261 \\
\hline & $\mathrm{X}_{2}$ & -0.129444 & 0.0521361 & 0.0133333 & 293.27 & 0 \\
\hline & $\mathrm{X}_{3}$ & -0.316111 & 0.0152111 & 0.0133333 & 85.56 & 0.0002 \\
\hline & $\mathrm{X}_{1} \mathrm{X}_{2}$ & 0.00042593 & 0.00036736 & 0.0133333 & 2.07 & 0.2101 \\
\hline & $\mathrm{X}_{1} \mathrm{X}_{3}$ & 0.00418519 & 0.00036736 & 0.0133333 & 49.88 & 0.0009 \\
\hline & $\mathrm{X}_{2} \mathrm{X}_{3}$ & 0.0227778 & 0.00116736 & 0.0133333 & 6.57 & 0.0505 \\
\hline \multirow[t]{7}{*}{$\mathrm{Y}_{2}$} & Constant & 0.877778 & & & & \\
\hline & $\mathrm{X}_{1}$ & -0.00914815 & 0.029184 & 0.0533333 & 10.26 & 0.0239 \\
\hline & $\mathrm{X}_{2}$ & -0.117778 & 1.13068 & 0.0533333 & 397.5 & 0 \\
\hline & $\mathrm{X}_{3}$ & 0.355556 & 0.054834 & 0.0533333 & 19.28 & 0.0071 \\
\hline & $\mathrm{X}_{1} \mathrm{X}_{2}$ & 0.00037037 & 0.00027778 & 0.0533333 & 0.1 & 0.7673 \\
\hline & $\mathrm{X}_{1} \mathrm{X}_{3}$ & 0.00307407 & 0.00478403 & 0.0533333 & 1.68 & 0.2513 \\
\hline & $\mathrm{X}_{2} \mathrm{X}_{3}$ & -0.168889 & 0.0641778 & 0.0533333 & 22.56 & 0.0051 \\
\hline \multirow[t]{7}{*}{$\mathrm{Y}_{3}$} & Constant & $1,620.06$ & & & & \\
\hline & $\mathrm{X}_{1}$ & -36.7463 & 128,283 & 115.667 & 9.59 & 0.027 \\
\hline & $\mathrm{X}_{2}$ & 180.444 & $1,81 \mathrm{E}+06$ & 115.667 & 135.55 & 0.0001 \\
\hline & $\mathrm{X}_{3}$ & 250.611 & $66,736.1$ & 115.667 & 4.99 & 0.0758 \\
\hline & $\mathrm{X}_{1} \mathrm{X}_{2}$ & 0.857407 & $1,488.67$ & 115.667 & 0.11 & 0.7522 \\
\hline & $\mathrm{X}_{1} \mathrm{X}_{3}$ & 18.0481 & 164,904 & 115.667 & 12.33 & 0.0171 \\
\hline & $\mathrm{X}_{2} \mathrm{X}_{3}$ & -445.278 & 446,113 & 115.667 & 33.34 & 0.0022 \\
\hline \multirow[t]{7}{*}{$\mathrm{Y}_{4}$} & Constant & 6.48889 & & & & \\
\hline & $\mathrm{X}_{1}$ & -0.0200741 & 0.0205444 & 0.0483333 & 8.79 & 0.0313 \\
\hline & $\mathrm{X}_{2}$ & -0.00638889 & 1.84507 & 0.0483333 & 789.8 & 0 \\
\hline & $\mathrm{X}_{3}$ & -0.967222 & 0.201751 & 0.0483333 & 86.36 & 0.0002 \\
\hline & $\mathrm{X}_{1} \mathrm{X}_{2}$ & 0.00535185 & 0.0580007 & 0.0483333 & 24.83 & 0.0042 \\
\hline & $\mathrm{X}_{1} \mathrm{X}_{3}$ & 0.00837037 & 0.0354694 & 0.0483333 & 15.18 & 0.0114 \\
\hline & $\mathrm{X}_{2} \mathrm{X}_{3}$ & 0.145556 & 0.0476694 & 0.0483333 & 20.41 & 0.0063 \\
\hline
\end{tabular}


significance of factors. The results of ANOVA for the four responses are listed in Table 4 where the $p$-value is the probability value used to determine the significant effects in the model. The effect was statistically significant for $p$-value less than 0.05 when a 95\% confidence level is considered [45]. Our results indicate that for $Y_{1}, Y_{2}$ and $Y_{4}, X_{2}$ was the most significant factor followed by $X_{3}$ then $X_{1}$. However, for the $Y_{3}, X_{2}$ was also the most significant factor followed by $X_{1}$ then $X_{3}$. The analysis revealed that $X_{2}-X_{3}$ interaction has significant effect on $\mathrm{Y}_{2}, \mathrm{Y}_{3}$ and $\mathrm{Y}_{4}$. Moreover, $\mathrm{X}_{1}-\mathrm{X}_{3}$ interaction has a significant effect on $\mathrm{Y}_{1}, \mathrm{Y}_{3}$ and $\mathrm{Y}_{4}$. Finally, $\mathrm{X}_{1}-\mathrm{X}_{2}$ interaction has significant effect on $\mathrm{Y}_{4}$. The relative importance of the main effects and their interactions was also studied using standardized main effect Pareto charts (Fig. 2). Each factor exceeding the vertical line is considered as statistically significant [46]. The $\% \mathrm{P}_{2} \mathrm{O}_{5}$ was found to be directly proportional to the temperature $\left(\mathrm{X}_{1}\right)$ and the interaction of $\mathrm{X}_{1}-\mathrm{X}_{2}$, while indirectly proportional to the volume of solution $\left(\mathrm{X}_{2}\right)$ and quantity of $\mathrm{PG}$ $\left(\mathrm{X}_{3}\right)$ as shown in Fig. 2(a). The temperature, volume of solution and the interaction $\mathrm{X}_{2}-\mathrm{X}_{3}$ have a strong negative effect on $\% \mathrm{~F}$ (Fig. 2(b)). The Pareto Chart of Fig. 2(c) for the TOC (mg.kg-1) shows that with the increase of the temperature and volume of solution the TOC decreases. Moreover, the interaction $\mathrm{X}_{2}-\mathrm{X}_{3}$ has a strong negative effect on the reduction of the TOC. However, the interaction $\mathrm{X}_{1}-\mathrm{X}_{3}$ has a strong positive effect on the reduction of the TOC. Actually, the $\mathrm{pH}$ is found to be directly proportional to the temperature $\left(\mathrm{X}_{1}\right)$, the volume of solution $\left(\mathrm{X}_{2}\right)$ and the interactions $\mathrm{X}_{1}-\mathrm{X}_{2}, \mathrm{X}_{2}-\mathrm{X}_{3}$ and $\mathrm{X}_{1}-\mathrm{X}_{3}$, while indirectly proportional to the quantity of PG (Fig. 2(d)).

After the elimination of insignificant parameters ( $p$-value $>$ 0.05) in Table 4, the final empirical models based on Eq. (1) at $95 \%$ confidence level can be represented as:

$$
\begin{aligned}
Y_{1}= & 1.319-0.006 X_{1}-0.129 X_{2}-0.316 X_{3}+0.004\left(X_{1} X_{3}\right) \\
Y_{2}= & 0.877-0.009 X_{1}-0.117 X_{2}+0.355 X_{3}-0.168\left(X_{2} X_{3}\right) \\
Y_{3}= & 1620.06-36.746 X_{1}+180.444 X_{2}+ \\
& 18.048\left(X_{1} X_{3}\right)-445.278\left(X_{2} X_{3}\right) \\
Y_{4}= & 6.488-0.20 X_{1}-0.006 X_{2}-0.967 X_{3}+0.005\left(X_{1} X_{2}\right)+ \\
& 0.008\left(X_{1} X_{3}\right)+0.145\left(X_{2} X_{3}\right)
\end{aligned}
$$

Removing the insignificant terms from the full model has produced the final models for each response that is more effective as a predictor of new data.

\subsection{Model Adequacy Checking}

The statistics used to test the adequacy of the models at confidence level of 95\% are summarized in Table 5. The coefficient of determination $\left(\mathrm{R}^{2}\right)$ evaluates the model suitability. It is accepted that for a good fit model, $\mathrm{R}^{2}$ should be in the range from 0.80 to 1. However, the use of adjusted R-squared (Adj- $\mathrm{R}^{2}$ ) is preferred to evaluate the model adequacy because it is adjusted for the number of factors in the model. The Adj- $\mathrm{R}^{2}$ may decrease if insignificant factors are added to the model. The regression model explains well the process when Adj- $\mathrm{R}^{2}$ is higher than 0.90 [47]. All the statistics given in Table 5 indicate that the estimated model for each response fits the experimental data adequately as the $\mathrm{R}^{2}$ varied between 0.98 and 0.99 and the $\mathrm{Adj}-\mathrm{R}^{2}$ between 0.95 and 0.99 .

Table 5. Statistics Used to Test the Adequacy of the Model

\begin{tabular}{ccccc}
\hline \multirow{2}{*}{ Statistics } & \multicolumn{4}{c}{ Response } \\
\cline { 2 - 5 } & $\mathbf{Y}_{\mathbf{1}}$ & $\mathbf{Y}_{\mathbf{2}}$ & $\mathbf{Y}_{\mathbf{3}}$ & $\mathbf{Y}_{\mathbf{4}}$ \\
\hline $\mathrm{R}^{2}$ & 0.98 & 0.99 & 0.98 & 0.99 \\
Adj-R $^{2}$ & 0.97 & 0.98 & 0.95 & 0.99 \\
\hline
\end{tabular}

\subsection{Three-dimensional Response Surface Plots}

Three-dimensional (3D) plots represent the simultaneous effect of any two factors on the response parameter, at a constant level of the third factor [48]. The temperature $\left(\mathrm{X}_{1}\right)$ and the quantity of $\mathrm{PG}\left(\mathrm{X}_{3}\right)$ did not significantly decrease the \% $\mathrm{P}_{2} \mathrm{O}_{5}$ (Figs. 3(a) and (b)). However, the $\% \mathrm{P}_{2} \mathrm{O}_{5}$ decreased when the volume of solution $\left(\mathrm{X}_{2}\right)$ increased (Figs. 3(a) and (c)). The \% $\mathrm{P}_{2} \mathrm{O}_{5}$ became lower when the temperature $\left(\mathrm{X}_{1}\right)$ was kept on the level of -1 $\left(30^{\circ} \mathrm{C}\right)$ (Figs. 3(a) and (b)). The lower \% $\mathrm{P}_{2} \mathrm{O}_{5}$ was achieved at a higher volume of solution $\left(\mathrm{X}_{2}\right)$ and at lower quantity of PG $\left(\mathrm{X}_{3}\right)$ (Fig. 3(c)).

The $\% \mathrm{~F}$ decreased when the temperature $\left(\mathrm{X}_{1}\right)$ and the volume of solution $\left(\mathrm{X}_{2}\right)$ were increased (Fig. 4(a)). The increase of the PG quantity $\left(\mathrm{X}_{3}\right)$ caused an increase in \% $\mathrm{F}$, which might be
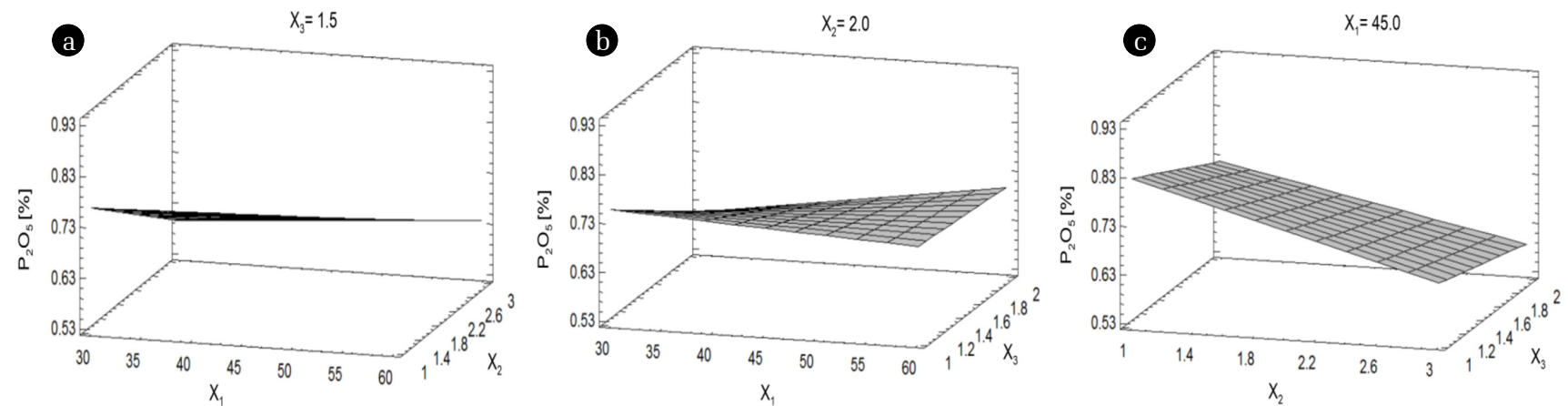

Fig. 3. Response surface plot of $P_{2} O_{5}$ reduction as a function of: (a) $X_{1}$ and $X_{2}$ at $X_{3}=1.5 \mathrm{~kg}$; (b) $X_{1}$ and $X_{3}$ at $X_{2}=2 L$; (c) $X_{2}$ and $X_{3}$ at $\mathrm{X}_{1}=45^{\circ} \mathrm{C}$. 

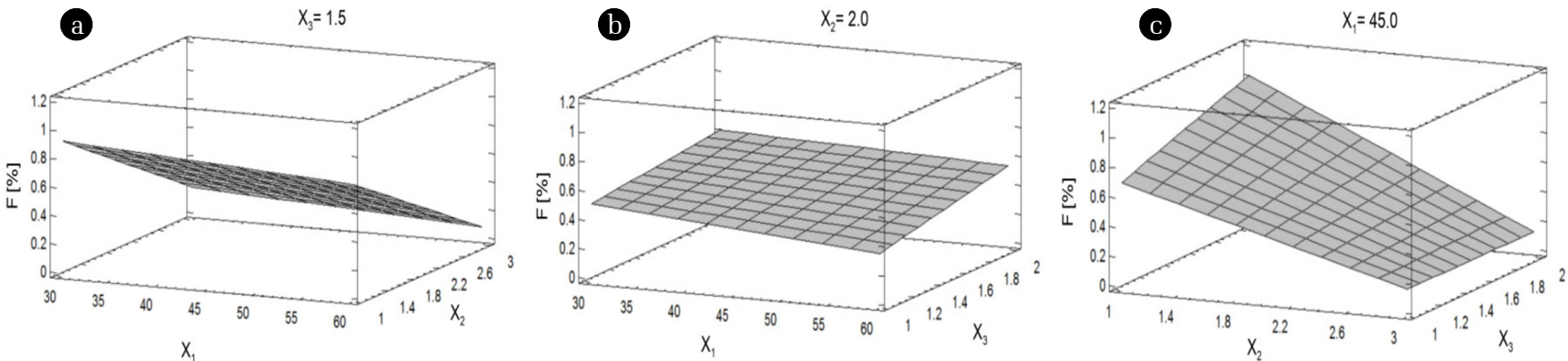

Fig. 4. Response surface plot of $F$ reduction as a function of: (a) $X_{1}$ and $X_{2}$ at $X_{3}=1.5 \mathrm{~kg}$; (b) $X_{1}$ and $X_{3}$ at $X_{2}=2 L$; (c) $X_{2}$ and $X_{3}$ at $X_{1}=45^{\circ} C$.
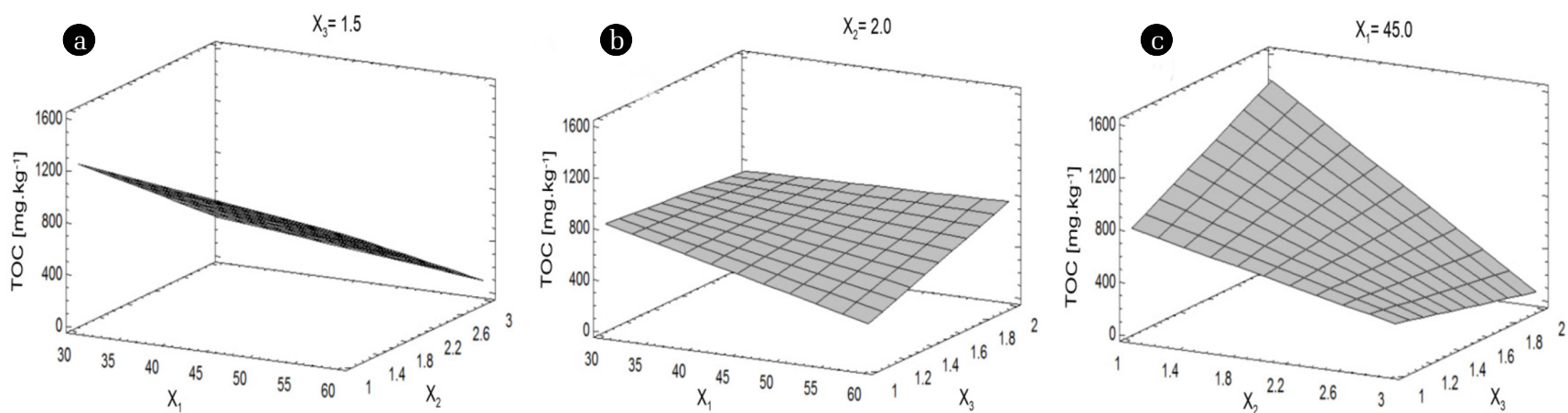

Fig. 5. Response surface plot of TOC reduction as a function of: (a) $X_{1}$ and $X_{2}$ at $X_{3}=1.5 \mathrm{~kg}$; (b) $X_{1}$ and $X_{3}$ at $X_{2}=2 L$; (c) $X_{2}$ and $X_{3}$ at $X_{1}=45^{\circ} C$.
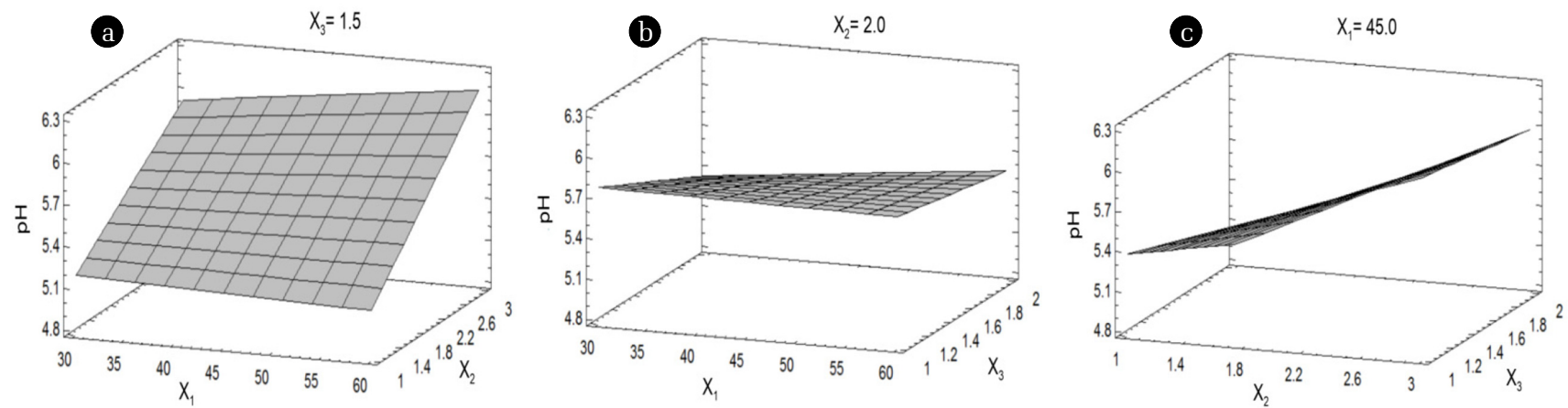

Fig. 6. Response surface plot of pH increase as a function of: (a) $X_{1}$ and $X_{2}$ at $X_{3}=1.5 \mathrm{~kg}$; (b) $X_{1}$ and $X_{3}$ at $X_{2}=2 \mathrm{~L}$; (c) $X_{2}$ and $X_{3}$ at $X_{1}=45^{\circ} \mathrm{C}$.

due to the addition of more PG, especially impurities that need to be eliminated (Fig. 4(b)). The lower \% F was acquired at a higher volume of solution $\left(\mathrm{X}_{2}\right)$ and at lower quantity of PG $\left(\mathrm{X}_{3}\right)$ (Fig. 4(c)).

The increase of the solution volume $\left(\mathrm{X}_{2}\right)$ caused the decrease in the TOC (Fig. 5(a) and (c)) and the increase in the PG quantity $\left(\mathrm{X}_{3}\right)$, in turn, caused the increase in the TOC due to the addition of more organic matter (Fig. 5(b)). The TOC became lower when the temperature $\left(\mathrm{X}_{1}\right)$ was kept on level $+1\left(60^{\circ} \mathrm{C}\right)$ (Figs. 5(a) and (b)) and the abutment TOC was observed at higher volume of solution $\left(\mathrm{X}_{2}\right)$ and lower quantity of $\mathrm{PG}\left(\mathrm{X}_{3}\right)$. The effect of solution volume $\left(\mathrm{X}_{2}\right)$ is the greatest one (Fig. 5(c)).

It is to be noted that the $\mathrm{pH}$ increased when the solution volume $\left(\mathrm{X}_{2}\right)$ was increased. This positive effect could be probably related to the solubility of impurities in the aqueous sulfuric acid solution such as $\mathrm{P}_{2} \mathrm{O}_{5}$. The temperature $\left(\mathrm{X}_{1}\right)$ and the quantity of $\mathrm{PG}$ did not significantly increase the $\mathrm{pH}$ (Figs. 6(a) and (b)). At the highest volume of solution $\left(\mathrm{X}_{2}\right)$, the $\mathrm{pH}$ increased with the increase in temperature $\left(\mathrm{X}_{1}\right)$. The higher $\mathrm{pH}$ was achieved at the higher volume of solution $\left(\mathrm{X}_{2}\right)$ and lower quantity of $\mathrm{PG}\left(\mathrm{X}_{3}\right)$ (Fig. 6(c)).

\subsection{Optimization of Process Parameters and Experimental Verification}

The aim of operating factors optimization, using FFD is to improve the purification process. The multi-response method named desirability function (DF) was applied for this purpose. This approach allows the combination of multiple responses into one response (DF) by the choice of a value between 0 to 1 .

This method comprises the following steps. First, for each response (Yi), a desirability score (di) is assigned by an appropriate function. Second, all individual desirability scores are combined on an overall desirability function (DF), which is optimized to 
Table 6. Comparison of Predicted Values of Responses and Experimentally Measured Values at Optimal Conditions

\begin{tabular}{ccc}
\hline Parameter & Predicted value & Experimental value \\
\hline $\mathrm{P}_{2} \mathrm{O}_{5}(\%)$ & 0.64 & 0.64 \\
$\mathrm{~F}(\%)$ & 0.07 & 0.1 \\
$\mathrm{TOC}(\mathrm{ppm})$ & 108 & 87 \\
$\mathrm{pH}$ & 6.2 & 6.2 \\
\hline
\end{tabular}

find the optimum set of parameters [49]. At the best point with maximum overall desirability of 0.9 , the optimum temperature, volume of solution and quantity of PG were found to be $60^{\circ} \mathrm{C}, 3 \mathrm{~L}$ and $1 \mathrm{~kg}$, respectively. Under the optimum conditions, the predicted values of $\mathrm{P}_{2} \mathrm{O}_{5}$, fluorine, TOC and $\mathrm{pH}$ were 0.64 (\%), 0.07 (\%), 108 ppm and 6.2, respectively. If compared to experimental values performed at optimized operating conditions of 0.64 (\%), 0.1 (\%), 87 ppm and 6.2, respectively (Table 6), the model predicted ones were approximately similar at the statistical significance level of $p<$ 0.05 , which induce an approving of the good prediction of the model.

Under these operating conditions, a mass balance was calculated and used for the verification of technical feasibility of the process. In the purification process, approximately 3 liters of diluted sulfuric acid solution are used for treating one kilogram of PG, containing $9.6 \%$ of free water. After filtration, approximately 3.6 liters are recovered and recycled in the purification process (Fig. 1). The 0.92 kilograms of obtained PG after purification, containing $20 \%$ free water, was dried at a temperature of $65^{\circ} \mathrm{C}$. Accordingly, the mass balance indicates that $81.4 \%$ of the brut PG went into the production of plaster and the rest went with the fine wastes.

\subsection{Characteristics of the Purified PG}

To investigate the performance of the purification process under optimum conditions, the main chemical components $\mathrm{P}_{2} \mathrm{O}_{5}, \mathrm{~F}$, TOC, $\mathrm{Na}_{2} \mathrm{O}+\mathrm{K}_{2} \mathrm{O}$ and the $\mathrm{pH}$ of the PG before and after purification are presented in Table 7. It can be seen that the purified PG complies with the requirements given in IS: 12679-1989, specification for gypsum use in plaster, blocks and boards [50].

The PG contents of heavy metals were analyzed using ICP spectroscopy before and after purification and given in Table 8 . The maximum drop was observed for $\mathrm{Cd}$ and $\mathrm{Zn}$ passed from 15 to $2 \mathrm{mg}$. $\mathrm{kg}^{-1}$ and from 100 to $14 \mathrm{mg}$. $\mathrm{kg}^{-1}$, respectively. The concentration of metals is comparable to that of the natural gypsum and well below the regulatory limits in Ajam (2010) [51], which justify the performance of the purification.

Several studies have reported that the radionuclide activity levels in the PG were concentrated in the fine fraction and were constituted a small percentage of the PG [52]. In the first step of PG purifying, a dilute acid is used to digest the PG. The pulp is shacked for a sufficient period. After that, during the floatation step the fine particles containing radioelements are removed. Then, the pulp is filtered and the remaining radio-elements are removed by the filtration step.

The activity concentration values of the radionuclides in PG samples before and after purification are summarized in Table 9. Hence, about 12.2, 36.5, 48.2 and $36.5 \%$ of Ra-226, Ac-228, Pb212 and Th-232, respectively, were successfully removed from the PG. The purified PG content of radionuclide elements $\left({ }^{226} \mathrm{Ra}\right.$, ${ }^{228} \mathrm{Ac},{ }^{232} \mathrm{Th},{ }^{40} \mathrm{~K}$ and ${ }^{212} \mathrm{~Pb}$ ) are below the limits fixed by the standards [53].

The analytical results showed a better removal of $\mathrm{P}_{2} \mathrm{O}_{5}$ than

Table 7. Main Chemical Components of the PG before and after Purification

\begin{tabular}{|c|c|c|c|}
\hline Constituents (wt. \%) & Raw PG & Purified PG & Constraints:IS: 12679- 1989 \\
\hline $\mathrm{P}_{2} \mathrm{O}_{5}$ & 1.54 & 0.65 & Max. 0.4 \\
\hline $\mathrm{F}$ & 1.3 & 0.12 & Max. 0.4 \\
\hline TOC & 0.7 & 0.01 & Max. 0.15 \\
\hline $\mathrm{Na}_{2} \mathrm{O}+\mathrm{K}_{2} \mathrm{O}$ & 0.3 & 0.04 & Max. 30 \\
\hline $\mathrm{pH}$ & 3.9 & 6.2 & Min. 5.0 \\
\hline
\end{tabular}

Table 8. Determination of the Impurity Present in PG before and after Purification

\begin{tabular}{|c|c|c|c|c|c|}
\hline Elements (mg. kg-1) & $\mathrm{Cr}$ & Cd & Mn & $\mathbf{V}$ & $\mathrm{Zn}$ \\
\hline Raw PG & 6 & 15 & 3 & 3 & 100 \\
\hline Purified PG & - & 2 & 2 & - & 14 \\
\hline Natural Gypsum & - & - & $1-2$ & - & $5-10$ \\
\hline Regulatory limits [51] & 90 to 180 & 1.2 to 2.4 & - & - & 276 to 552 \\
\hline
\end{tabular}

Table 9. Radionuclide Activity Levels in PG before and after Purification

\begin{tabular}{cccccc}
\hline Elements (Bq.kg ${ }^{-1}$ ) & Ra-226 & Ac-228 & Pb-212 & Th-232 & K-40 \\
\hline Raw PG & $246.45 \pm 6.29$ & $24.83 \pm 2.47$ & $8.09 \pm 1.33$ & $24.83 \pm 2.47$ & $13.12 \pm 3.34$ \\
Purified PG & $216.22 \pm 6.2$ & $15.75 \pm 2.24$ & $4.19 \pm 1.22$ & $15.75 \pm 2.24$ & $15.56 \pm 2.59$ \\
Upper limit & 10,000 & 10,000 & 10,000 & 1,000 & 100,000 \\
\hline
\end{tabular}


Table 10. Physical Properties of Gypsum Plaster

\begin{tabular}{cccccccc}
\hline \multirow{2}{*}{ Sample } & Plaster origin & Consistency (\%) & \multicolumn{2}{c}{ Setting time (min) } & \multicolumn{2}{c}{ Compressive strength } & Expansion (\%) \\
& & & Initial & Final & (MPa) & 0.04 \\
1 & Purified PG & 91 & 6.30 & 19.00 & 4.64 & 0.05 \\
2 & Natural gypsum & 74 & 7.00 & 20.00 & 4.1 & - \\
\hline
\end{tabular}

that obtained by Van Der Merwe and Strydom [26] for stirring PG in sulfuric acid (5\%) for $30 \mathrm{~min}$ at ambient temperature and a solid/liquid ratio of 1:4. Also, these values are higher than reported by Jarosinski et al [25] for the removal of Fluor from PG by treating PG with a $10 \%$ sulfuric acid solution.

\subsection{Production of Plaster from Purified PG}

After purification of PG under optimum conditions, the reduction of impurities conformed with the requirement as given in IS: 12679-1989, specification for byproduct gypsum for using plaster blocks and board. The Gypsum plaster $\left(\mathrm{CaSO}_{4} .1 / 2 \mathrm{H}_{2} \mathrm{O}\right)$ was produced by calcining purified PG at $130-170^{\circ} \mathrm{C}$ for $4 \mathrm{~h}$. The plaster was tested for various physical properties according to the French Standard EN 13279-2 (Part 2) [54]. The comparative physical properties (consistency, setting time, compressive strength and expansion) of the obtained gypsum plaster from natural gypsum and the purified PG are given in Table 10. The plaster produced with purified PG was found to have similar physical properties to those produced from natural gypsum and conform to the French standard EN 13279-1 specifications [55]. This proved the efficiency of the purification methodology to remove the impurities to a large extent. The plaster produced with purified PG was found to have a higher consistency than that obtained from natural gypsum. This was due to the fine size distribution of PG. Hence, the gypsum plaster can be used for building products like boards, blocks, bricks and a variety of cement binders.

\section{Conclusions}

The accumulation of PG causes environmental threats and storage problems. In order to valorize the huge accumulated quantities, several processes are used to remove impurities. These processes are based specially on the treatment of PG using sulfuric acid solutions. However, these studies have reported that the temperature, the volume of aqueous sulfuric acid solution and the quantity of PG were the most examined factors affecting the PG purification. There is no example in the literature helps to understand how these factors influence the purification process. Also, no research can determine and statistically evaluate the interrelationship among the process factors. In the present research work, an experimental process using diluted sulfuric acid was developed and optimized to purify the PG. A $2^{3}$ full factorial design methodology was used to evaluate the main effects and interaction effects of temperature, volume of aqueous sulfuric acid solution and PG quantity. The $\% \mathrm{P}_{2} \mathrm{O}_{5}, \% \mathrm{~F}$, TOC $\left(\mathrm{mg} \mathrm{kg}^{-1}\right)$ and $\mathrm{pH}$ were selected as the response variables of the model design. The factorial design results showed that the optimum conditions of temperature, volume of aqueous sulfuric acid solution and PG quantity were found to be $60^{\circ} \mathrm{C}, 3 \mathrm{~L}$ and $1 \mathrm{~kg}$, respectively. The process of purification was performed under optimum conditions, the impurities $\left(\mathrm{P}_{2} \mathrm{O}_{5}\right.$, $\mathrm{F}$, and TOC) decreased and the $\mathrm{pH}$ increased. The analysis by ICP has proven that the major toxic impurities are reduced after purification. Under the optimum conditions, the predicted values of $\mathrm{P}_{2} \mathrm{O}_{5}$, fluorine, TOC and $\mathrm{pH}$ were validated by comparison to experimental values and a statistically high level of similarity is recognized. The purified PG can produce gypsum plaster $\left(\mathrm{CaSO}_{4} \cdot 1 / 2 \mathrm{H}_{2} \mathrm{O}\right)$ of improved setting and strength characteristics. The plaster can be used as building materials.

\section{References}

1. Reijnders L. Cleaner phosphogypsum, coal combustion ashes and waste incineration ashes for application in building materials: A review. Build. Environ. 2007;42:1036-1042.

2. El Afifi EM, Hilal MA, Attallah MF, EL-Reefy SA. Characterization of phosphogypsum wastes associated with phosphoric acid and fertilizers production. J. Environ. Radioact. 2009;100:407-412.

3. Kuryatnyk T, Angulski da Luz C, Ambroise J, Pera J. Valorization of phosphogypsum as hydraulic binder. J. Hazard. Mater. 2008;160:681-687.

4. Hassen S, Anna Z, Elaloui EE, Belgacem MN, Mauret E. Study of the valorization of phosphogypsum in the region of Gafsa as filler in paper. IOP Conf. Ser.: Mater. Sci. Eng. 2012;28: 012018.

5. Hammas I, Horchani-Naifer K, Férid M. Characterization and optical study of phosphogypsum industrial waste. Stud. Chem. Process Technol. (SCPT) 2013;1:30-36.

6. Yang J, Liu W, Zhang L, Xiao B. Preparation of load-bearing building materials from autoclaved phosphogypsum. Constr. Build. Mater. 2009;23:687-693.

7. Ajam L, Ouezdou MB, Felfoul HS, El Mensi R. Characterization of the Tunisian phosphogypsum and its valorization in clay bricks. Constr. Build. Mater. 2009;23:3240-3247.

8. Rutherford PM, Dudas MJ, Samek RA. Environmental impacts of phosphogypsum: A review. Sci. Total Environ. 1994;149:1-38.

9. Zairi M, Rouis MJ. Impacts environnementaux du stockage du phosphogypse à Sfax (Tunisie). BLPC. 1999;219:29-40.

10. Tayibi H, Choura M, Lopez FA, Alguacil, FJ, Lopez-Delgado A. Environmental impact and management of phosphogypsum. J. Environ. Manage. 2009;90:2377-2386.

11. Taher MA. Influence of thermally treated phosphogypsum on the properties of Portland slag cement. Resour. Conserv. 
Recy. 2007;52:28-38.

12. Parreira, AB, Kobayashi ARK, Silvestre Jr OB. Influence of Portland cement type on unconfined compressive strength and linear expansion of cement-stabilized phosphogypsum. J. Environ. Eng. 2003;129:956-960.

13. Zhoua J, Gaob H, Shub Z, Wangb Y, Yan C. Utilization of waste phosphogypsum to prepare non-fired bricks by a novel Hydration-Recrystallization process. Constr. Build. Mater. 2012;34:114-119.

14. Potgieter JH, Potgieter SS, McCrindle RI, Strydom CA. An investigation into the effect of various chemical and physical treatments of a South African phosphogypsum to render it suitable as a set retarder for cement. Cement Concrete Res. 2003;33:1223-1227.

15. Smadi MM, Haddad RH, Akour AM. Potential use of phosphogypsum in concrete. Cement Concrete Res. 1999;29:1419-1425.

16. Manjit S, Garg M. Making of anhydrite cement from waste gypsum. Cement Concrete Res. 2000;4:571-577.

17. Manjit S, Garg M. Production of beneficiated phosphogypsum for cement manufacture. J. Sci. Ind. Res. 2002;61:533-537.

18. Altun IA, Sert Y. Utilization of weathered phosphogypsum as set retarder in Portland cement. Cement Concrete Res. 2004;34:677-680.

19. Sfar Felfoul H. Etude du phosphogypse de Sfax (Tunisie) en vue d'une valorisation en technique routière [dissertation]. Department of Civil Engineering. National Engineering School of Tunis/INSA Toulouse; 2004.

20. Degirmenci N, Okucu A, Turabi A. Application of phosphogypsum in soil stabilization. Build. Environ. 2007;42:3393-3398.

21. Ahmadi BH. Use of high strength by product gypsum bricks in masonry construction. [dissertation]. Florida, USA: Univ. of Miami, Coral Gables; 1989.

22. Kumar SA. Perspective study on fly ash-lime-gypsum bricks and hollow blocks for low cost housing development. Constr. Build. Mater. 2002;16:519-525.

23. Manjit S. Treating waste phosphogypsum for cement and plaster manufacture. Cement Concrete Res. 2002;32:1033-1038.

24. Hammas-Nasri I, Horchani-Naifer K, Férid M. Rare earths concentration from phosphogypsum waste by two-step leaching method. Int. J. Miner. Process. 2016;149:78-83.

25. Jarosinski A, Kowalczyk J, Mazanek C. Development of the Polish wasteless technology of apatite phosphogypsum utilization with recovery of rare-earths. J. Alloy. Compd. 1993;200:147-150.

26. Van der Merwe EM, Strydom CA. Purification of South African PG for use as Portland cement retarder by a combined thermal and sulphuric acid treatment method. S. Afr. J. Sci. 2004;100:411-414.

27. Lokshin EP, Tareeva OA, Elizarova IR. On integrated processing of phosphogypsum. Russ. J. Appl. Chem. 2013;86:463-468.

28. Lokshin EP, Tareeva OA. Production of high-quality gypsum raw materials from phosphogypsum. Russ. J. Appl. Chem. 2015;88:567-573.

29. Aliedeh MA, Jarrah NA. Application of full factorial design to optimize phosphogypsum beneficiation process $\left(\mathrm{P}_{2} \mathrm{O}_{5}\right.$ Reduction) by using sulfuric and nitric acid solutions. Sixth Jordanian International Chemical Engineering Conference,
Amman, Jordan. March 2012.

30. Kandil AHT, Cheira MF, Gado HS, Soliman MH, Akl HM. Ammonium Sulfate preparation from phosphogypsum waste. J. Radiat. Res. Appl. Sci. 2017;10:24-33.

31. Veličković AV, Stamenković OS, Todorović ZB, Veljković VB. Application of the full factorial design to optimization of base-catalyzed sunflower oil ethanolysis. Fuel 2013;104: 433-442.

32. Yi XS, Shi WX, Yu SL, Li XH, Sun N, He C. Factorial design applied to flux decline of anionic polyacrylamide removal from water by modified polyvinylidene fluoride ultrafiltration membranes. Desalination 2011;274:7-12.

33. Sadhukhan S, Sarkar U. Production of biodiesel from Crotalaria juncea (Sunn-Hemp) oil using catalytic trans-esterification: Process optimisation using a factorial and BoxBehnken design. Waste Biomass Valori. 2016;7:343-355.

34. Bingol D, Tekin N, Alkan M. Brilliant Yellow dye adsorption onto sepiolite using a full factorial design. Appl. Clay Sci. 2010;50:315-321.

35. Valipour M, Banihabib ME, Behbahani SMR. Comparison of the ARMA, ARIMA, and the autoregressive artificial neural network models in forecasting the monthly inflow of Dez dam reservoir. J. Hydrol. 2013;476:433-441.

36. Valipour M. Study of different climatic conditions to assess the role of solar radiation in reference crop evapotranspiration equations. Arch. Agron. Soil Sci. 2015;61:679-694.

37. Valipour M. How much meteorological information is necessary to achieve reliable accuracy for rainfall estimations. Agriculture 2016;6:53.

38. Valipour M. Global experience on irrigation management under different scenarios. J. Water Land Dev. 2017;32:95-102.

39. Valipour M. Variations of land use and irrigation for next decades under different scenarios. Irriga: Braz. J. Irrig. Drain. 2016;1:262-288.

40. Valipour M, Sefidkouhi MAG, Sarjaz MR. Selecting the best model to estimate potential evapotranspiration with respect to climate change and magnitudes of extreme events. Agr. Water Manage. 2017;180:50-60.

41. Nejad SJ, Abolghasemia H, Moosaviana MA, Maraghehb MG. Fractional factorial design for the optimization of supercritical carbon dioxide extraction of $\mathrm{La}^{3+}, \mathrm{Ce}^{3+}$ and $\mathrm{Sm}^{3+}$ ions from a solid matrix using bis (2,4,4-trimethylpentyl) dithiophosphinic acid + tributylphosphate. Chem. Eng. Res. Des. 2011; 8:827-835.

42. StatPoint Inc. Statgraphics Centurion XVI user manual. United States of America 2005.

43. Heiderscheidt E, Leiviska T, Kløve B. Chemical treatment response to variations in non-point pollution water quality: Results of a factorial design experiment. J. Environ. Manage. 2015;150:164-172.

44. Shahabadi MSS, Reyhani A. Optimization of operating conditions in ultrafiltration process for produced water treatment via the full factorial design methodology. Sep. Purif. Technol. 2014;132:50-61.

45. Pey CM, Maestro A, Solé I, Gonzàlez C, Solans C, Gutiérrez JM. Optimization of nano-emulsions prepared by low-energy emulsification methods at constant temperature using a facto- 
rial design study. Colloid. Surface. A. 2006;288:144-150.

46. Zhou G, Fu L, Li X. Optimisation of ultrasound-assisted extraction conditions for maximal recovery of active monacolins and removal of toxic citrinin from red yeast rice by a full factorial design coupled with response surface methodology. Food Chem. 2015;170:186-192.

47. Onsekizoglua P, Bahcecib KS, Acara J. The use of factorial design for modeling membrane distillation. J. Membrane Sci. 2010;349:225-230.

48. Shah M, Pathak K. Development and statistical optimization of solid lipid nanoparticles of simvastatin by using $2^{3}$ full-factorial design. AAPS PharmSciTech 2009;11:489-496.

49. Figueroa RAR, Cassano A, Drioli E. Ultrafiltration of orange press liquor: optimization for permeate flux and fouling index by response surface methodology. Sep. Sci. Technol. 2011;80: 1-10.
50. IS. 12679-1989. Specification for by-product gypsum for use in plaster, blocks and boards. Bureau of Indian Standards, New Delhi; 1989.

51. Ajam L. Valorisation du phosphogypse dans la brique cuite Cas des terrils de Sfax (Tunisie) [Doctorate Thesis]. Tunisia : Univ. of Tunis El Manar; 2010.

52. El-Didamony H, Ali MM, Awwad NS, Fawzy MM, Attallah MF. Treatment of phosphogypsum waste using suitable organic extractants. J. Radioanal. Nucl. Chem. 2012;291:907-914.

53. EURATOM. Council Directive 96/26 EC. European Atomic Commission; 1996.

54. NF EN 13279-2. Liants-plâtres et enduits à base de plâtre pour le bâtiment - Partie 2 : méthodes d'essai 2004 [in French].

55. NF EN 13279-1. Liants-plâtres et enduits à base de plâtre pour le bâtiment - Partie 1 : définitions et exigences 2008 [in French]. 